\title{
Article \\ Experimental Study of Biogas-Hydrogen Mixtures Combustion in Conventional Natural Gas Systems
}

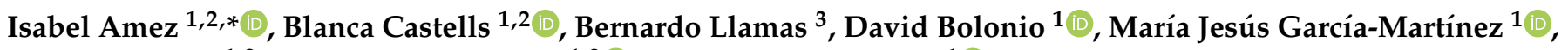 \\ José L. Lorenzo ${ }^{1,2}$, Javier García-Torrent ${ }^{1,2}$ (I) and Marcelo F. Ortega ${ }^{1}{ }^{1(D)}$ \\ 1 Department of Energy and Fuels, E.T.S. Ingenieros de Minas y Energía, Universidad Politécnica de Madrid, \\ 28003 Madrid, Spain; b.castells@upm.es (B.C.); david.bolonio@upm.es (D.B.); mj.garcia@upm.es (M.J.G.-M.); \\ joseluis.lorenzo.bayona@upm.es (J.L.L.); javier.garciat@upm.es (J.G.-T.); mf.ortega@upm.es (M.F.O.) \\ 2 Laboratorio Oficial JM Madariaga (LOM), Universidad Politécnica de Madrid, 28003 Madrid, Spain \\ 3 Department of Geological and Mining Engineering, E.T.S. Ingenieros de Minas y Energía, \\ Universidad Politécnica de Madrid, Ríos Rosas 21, 28003 Madrid, Spain; bernardo.llamas@upm.es \\ * Correspondence: isabel.amez@upm.es
}

check for updates

Citation: Amez, I.; Castells, B.; Llamas, B.; Bolonio, D.; GarcíaMartínez, M.J.; Lorenzo, J.L.; García-Torrent, J.; F. Ortega, M. Experimental Study of BiogasHydrogen Mixtures Combustion in Conventional Natural Gas Systems. Appl. Sci. 2021, 11, 6513. https:// doi.org/10.3390/app11146513

Academic Editors: Michael Kühn, Sonja Martens and Viktor Bruckman

Received: 15 June 2021

Accepted: 13 July 2021

Published: 15 July 2021

Publisher's Note: MDPI stays neutral with regard to jurisdictional claims in published maps and institutional affiliations.

Copyright: (c) 2021 by the authors. Licensee MDPI, Basel, Switzerland. This article is an open access article distributed under the terms and conditions of the Creative Commons Attribution (CC BY) license (https:/ / creativecommons.org/licenses/by/ $4.0 /)$.
Featured Application: The results of this study show that the addition of hydrogen to biogas in small quantities allows the reuse of conventional natural gas systems to burn biogas. This lowers costs and promotes the circular economy.

Abstract: Biogas is a renewable gas with low heat energy, which makes it extremely difficult to use as fuel in conventional natural gas equipment. Nonetheless, the use of hydrogen as a biogas additive has proven to have a beneficial effect on flame stability and combustion behavior. This study evaluates the biogas-hydrogen combustion in a conventional natural gas burner able to work up to $100 \mathrm{~kW}$. Tests were performed for three different compositions of biogas: BG70 $\left(30 \% \mathrm{CO}_{2}\right), \mathrm{BG} 60$ $\left(40 \% \mathrm{CO}_{2}\right)$, and BG50 (50\% $\left.\mathrm{CO}_{2}\right)$. To achieve better flame stability, each biogas was enriched with hydrogen from $5 \%$ to $25 \%$. The difficulty of burning biogas in conventional systems was proven, as the burner does not ignite when the biogas composition contains more than $40 \%$ of $\mathrm{CO}_{2}$. The best improvements were obtained at $5 \%$ hydrogen composition since the exhaust gas temperature and, thus, the enthalpy, rises by $80 \%$ for BG70 and $65 \%$ for BG60. The stability map reveals that pure biogas combustion is unstable in BG70 and BG60; when the $\mathrm{CO}_{2}$ content is $50 \%$, ignition is inhibited. The properties change slightly when the hydrogen concentrations are more than $20 \%$ in the fuel gas and do not necessarily improve.

Keywords: hydrogen addition; biogas; biogas combustion; renewable fuels; combustion behavior; temperature behavior

\section{Introduction}

Climate instability produced by anthropogenic activities reinforces the necessity to seek new renewable sources to minimize greenhouse gas (GHG) emissions. The biggest contributors to global warming are carbon dioxide and methane emissions [1]. Consequently, all efforts to mitigate the current environmental crisis are focused on reducing carbon emissions. The ambitious environmental targets proposed by the European Commission and the 2050 targets are forcing a technological revolution to reduce human impact. This revolution is currently supported by public and private investments, although these resources are not within the reach of all companies [2]. However, thanks to the "green recovery" plan promoted by the European Union and other countries around the world, the COVID-19 crisis can be a great opportunity and a turning point for energy transition [3]. Hence, in the last decades, renewable energy research has been in the scientific spotlight, mainly focused on the fight against climate change, the fast growth of energy demand, and the depletion of fossil fuels. Renewable gases, notably hydrogen, biomethane and biogas, 
cover a wide range of possibilities. The use of renewable gases may solve some of the most important environmental problems registered in the automotive or energetic sector, and it could help reach the ambitious "zero emissions objective" [4-7]. Energy supply and transport sector are some of the greatest contributors to GHG emissions with $24.9 \%$ and $18.1 \%$, respectively [8].

In this scenario, biogas is an alternative and sustainable solution. Biogas is produced by the fermentation or anaerobic digestion of organic waste, such as wood, agricultural products, manure, etc., which is, in other words, biodegradable waste [9]. It is precisely the origin of biogas that makes it a potentially carbon-neutral resource, despite containing a high percentage of carbon dioxide, which can vary between $30 \%$ and $50 \%[10,11]$. Biogas consumption and electricity generation from organic wastes are developed technologies already available in the current market. Nevertheless, in Europe, only about $28 \%$ of the organic waste is valorized or recycled, which means that there is a great potential for improvement [9]. The main reason for this low valorization lies in the strong limitation of biogas utilization, due to its low heating value, caused by the carbon dioxide content and the strong fuel variabilities [12]. Additionally, carbon dioxide affects the combustion process, hampering flame creation and flame stabilization in conventional systems [13]. It is also important to mention the need for proper reactor design to optimize biogas production, as well as the long residence times required to complete the process [14]. All the above challenge the promotion of the use of biogas, which has to overcome significant technical and economic barriers to become a reliable renewable energy source. Conversely, biomethane is composed mainly of methane $\left(96-99 \%\right.$ of $\left.\mathrm{CH}_{4}\right)$; therefore, it can be considered a natural gas. Currently, biomethane injection into the natural gas grid has the largest potential use in Europe. Its versatility makes it possible to reuse the current pipeline infrastructures and the conventional combustion systems [15]. However, some local studies showed that composting and biogas production gather the same perspective level [16] and, consequently, the present research focuses on biogas optimization for distributed direct uses.

Besides biogas, hydrogen has been gaining great importance in the past decades due to its versatility and its high yield rates, which may boost energy transition. Currently, approximately $95 \%$ of hydrogen can be labeled as blue or grey hydrogen [17]. However, to contribute to the decarbonization of conventional energy systems, hydrogen needs to be produced from renewable sources. Both biogas and hydrogen need large investments in transport and distribution infrastructures, so are currently limited to distributed generation direct uses. This study investigates the possibility of combining both and, thus, accelerate its technical implementation.

Hydrogen enrichment is a technique that may allow the harnessing of renewable fuels into conventional combustion systems [18,19]. In recent times, enriched natural gas combustion behavior has been widely studied. Hydrogen injection into conventional gas fuels reduces heat release oscillations and improves flame stability [20-22], while enhancing turbulent explosion parameters [21]. It has, indeed, been noticed that with $5 \%$ hydrogen, the flame expands greatly, inhibiting combustion instability [23]. All studies highlight that hydrogen concentration is a crucial parameter in all flammability and combustion characteristics [24]. Small percentages of hydrogen improve global efficiency in some combustion processes, while large amounts may change the flame typology, decreasing the combustion quality $[25,26]$. This also implies an increase in pollutant emissions despite the numerous studies that stated that GHG emissions are reduced when hydrogen-methane mixtures are used [27]. Usually, the studied percentages of hydrogen content are between 0 and $50 \%$ [28].

The enrichment of biogas, as well as the dual interaction of $\mathrm{H}_{2} / \mathrm{CO}_{2}$ mixtures, has been recently studied [29]. Flame stability is one of the biggest disadvantages of biogas combustion. However, H.S. Zhen et al. [18] observed a favorable effect of hydrogen addition on flame stability and a detrimental effect of carbon dioxide concentration. This might be partly explained by the widening of the biogas flammability limits caused by the 
added hydrogen. The favorable results of previous studies has encouraged the research of biogas-hydrogen blends in other combustion systems, such as combustion engines or power-to-methane cycles [30,31]. The results agree with former research works, proving the increase in detonation characteristics of biogas by adding hydrogen percentages between 0 and $20 \%$ [32]. Most of the research works focused on investigating the intrinsic properties of combustion by using experimental laboratory devices. However, this study intends to evaluate the combustion behavior in conventional combustion systems currently available in the market. The importance of tests on conventional energy systems resides in the necessity to boost the circular economy by reusing current equipment to burn renewable fuels. Industrial processes are large heat and electric energy consumers; therefore, their decarbonization is a key point to reduce greenhouse emissions [33]. Combustion systems in industry are typically expensive, due to their generation capacity and, consequently, their size. The replacement of these systems implies large investments that sometimes companies cannot afford. Then, the possibility to reuse conventional burners, boilers, or engines for energy conversion could be the key to a sustainable future, and an easier circular economy. Additionally, the replacement of conventional equipment for systems adapted to renewable fuels is also expensive for end consumers.

As mentioned above, combustion tests are generally carried out on small-scale laboratory equipment [18,34-36]. Yan Zhao et al. [37] investigated the influence of renewable gas content on the operating performance of conventional combustion devices, such as room furnaces. They evaluated the effect of adding $\mathrm{CO}_{2}$ or $\mathrm{H}_{2}$ to natural gas in a representative furnace with a heating load from $15.4 \mathrm{~kW}$ to $22.0 \mathrm{~kW}$. The results reflected the necessity to test the combustion parameters in high-power heating devices [37]. Hence, the present study addresses a conventional combustion system behavior, consisting of a burner and a combustion chamber of $100 \mathrm{~kW}$ fed with biogas-hydrogen mixtures instead of natural gas. Combustion efficiency parameters, such as exhaust gas temperature, emissions, and ignition behavior, were investigated. In this study, combustion or system behavior is understood as the variation of the combustion parameters controlled in the experimental setup, such as temperature and exhaust gas composition, as well as combustion stability and durability. First, the effect of $\mathrm{CO}_{2}$ addition to natural gas was experimentally analyzed. Then, the tests were performed with three different compositions of biogas: rich biogas 70:30 $\mathrm{CH}_{4}: \mathrm{CO}_{2}$ (BG70), standard biogas 60:40 $\mathrm{CH}_{4}: \mathrm{CO}_{2}(\mathrm{BG} 60)$ and poor biogas $50: 50 \mathrm{CH}_{4}: \mathrm{CO}_{2}$ (BG60). Finally, with the aim to encourage better flame stability, each biogas was enriched with hydrogen from $5 \%$ to $25 \%$. The results establish the operation conditions of conventional combustion systems when fed with renewable fuels.

\section{Materials and Methods}

We analyzed the behavior of renewable gases (Air Liquide, Madrid, Spain) and their mixtures in a conventional combustion chamber (Lasian, Zaragoza, Spain). To do that, the experimental system is designed to simulate a combustion industrial process to obtain heat/electricity. Normally, the main limitation in combined cycle power plants comes from the turbine design, specifically from the materials working temperature [38]. In fact, hydrogen (Air Liquide, Madrid, Spain) addition is currently limited not only by the cost increase, but also by the combustion heat rise. Hence, although biogas combustion temperatures are significatively lower than natural gas temperatures, the exhaust temperature is an important parameter in combustion systems engineering. Even though material limitation is important in equipment design, this study intends to evaluate the combustion behavior by analyzing the exhaust gas temperature. The combustion temperature is also an essential parameter considered in efficiency analysis since greater temperatures imply greater enthalpies and, consequently, greater combustion efficiency [39].

\subsection{Combustion Chamber and Burner Selection}

Carbon dioxide (Air Liquide, Madrid, Spain) and hydrogen addition to methane or natural gas (Naturgy, Madrid, Spain) are normally tested in laboratory devices or 
low-power appliances, focusing mainly on flame stability. [37]. The lack of experimental data focused on high-power appliances determined the equipment selection in this study. Hence, a burner and a combustion chamber with a heating load ranging from $25 \mathrm{~kW}$ to $100 \mathrm{~kW}$ were selected for the experimental setup. The gas burner is a Bentone BFG1 H3 (Bentone, Näsvägen, Sweden), designed according to the European standard EN 676 [40] to consume natural gas. The experimental setup was installed in the facilities of the Laboratorio Oficial Madariaga (LOM). The control unit regulates two slow opening gas valves, enabling both the on/off and 2 stage operation. The burner ignition and flame detection are monitored according to the ionization principle [41]. An incorrect gas-air mixture can be the cause of poor ionization current that leads to an ignition failure. To prevent this failure, the ionization current needs to be set at more than $15 \mu \mathrm{A}$. The combustion chamber is dimensioned to contain a $100 \mathrm{~kW}$ flame and its geometry is outlined in Figure 1. The combustion chamber materials endure temperatures of $800{ }^{\circ} \mathrm{C}$ at $2000 \mathrm{KPa}$. The refrigeration circuit is externally concentrical and enables safe operating.

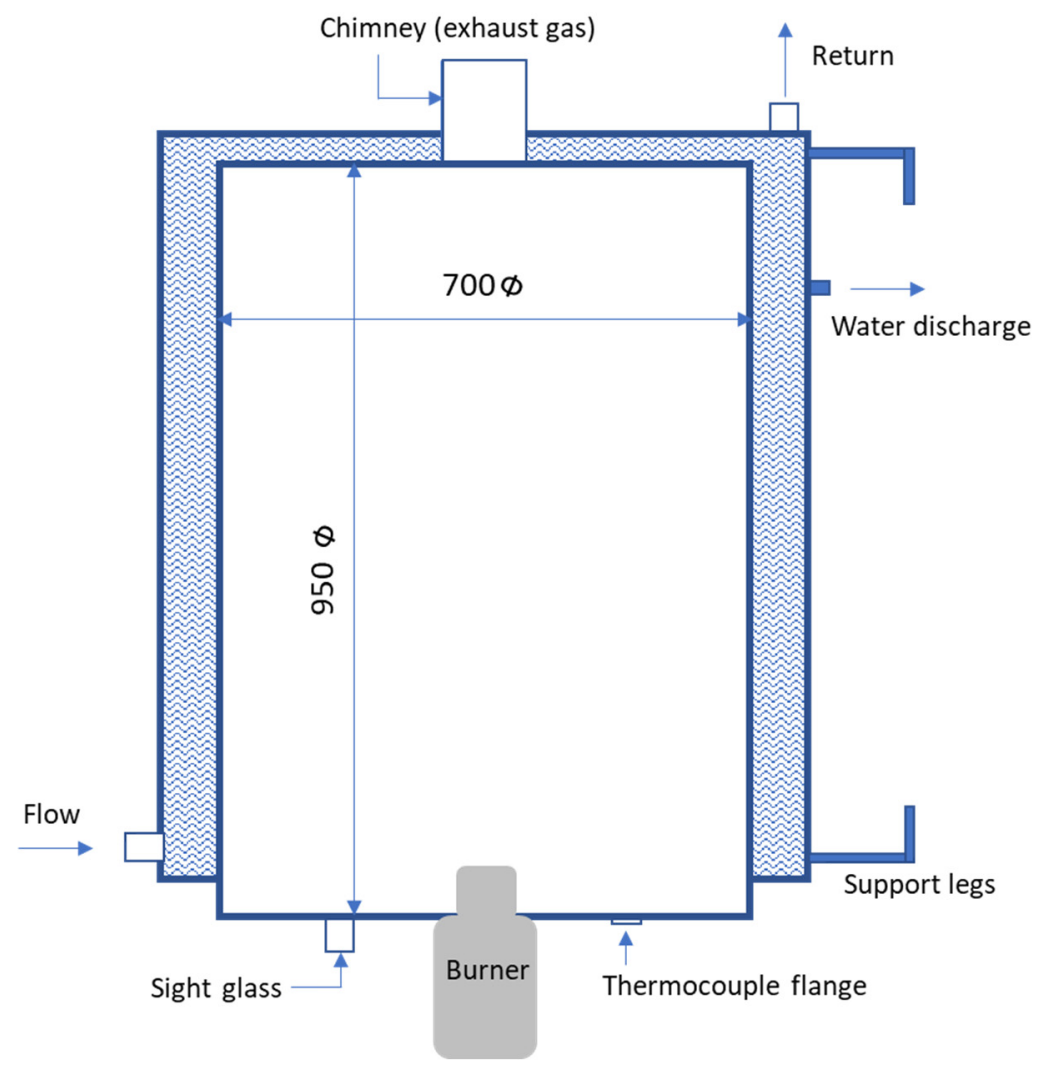

Figure 1. Combustion chamber outline and dimensions ( $\mathrm{mm})$.

\subsection{Experimental Setup}

Natural gas, hydrogen and carbon dioxide are mixed in mass controllers (model Brooks 5800S, (Brooks Instrument, Hatfield, PA, USA), purposely installed in a mixer box. Therefore, biogas is simulated as a mixture of natural gas and carbon dioxide. The operation gauge pressure is the average natural gas pipeline pressure in Spain (20 mbar). The fuel mixture supplies the burner inlet at 3.68 mbar, regulated down to a maximum inlet pressure of 4 mbar. The gas burner is an aspirated burner fed with atmospheric air from an integrated built-in fan. The fuel and oxidant consumption can be varied to obtain different heating loads. Consequently, fuel consumption varies from $2.65 \mathrm{Nm}^{3} / \mathrm{h}$ to $10.58 \mathrm{Nm}_{3} / \mathrm{h}$. Even though the maximum heating load of the burner is $100 \mathrm{~kW}$, the operability conditions of the setup makes it possible to work at $33 \mathrm{~kW}$. The gas burner is installed in the combustion chamber, designed to contain a $100 \mathrm{~kW}$ flame. A pipeline conducts the exhaust gas stream directly into the chimney. The data acquisition unit and 
the thermocouple are installed $1.2 \mathrm{~m}$ from the exhaust gas outlet. This unit measures the $\mathrm{CO}_{2}$ and $\mathrm{O}_{2}$ content, as well as the combustion lambda $(\lambda)$. The lambda factor determines the air/fuel ratio, where one is the stoichiometric ratio of the mixture. The system pressure is controlled by two-gauge measures to ensure that the maximum operating point is not exceeded. The purpose of the common room furnaces lies on the heat transfer between the flame and the carrier fluid. However, this study is focused on exhaust gas temperatures, and thus, the combustion chamber refrigeration is externally concentrical. Figure 2 outlines the combustion system experimental setup scheme (Figure 2a) and the equipment used (Figure 2b).

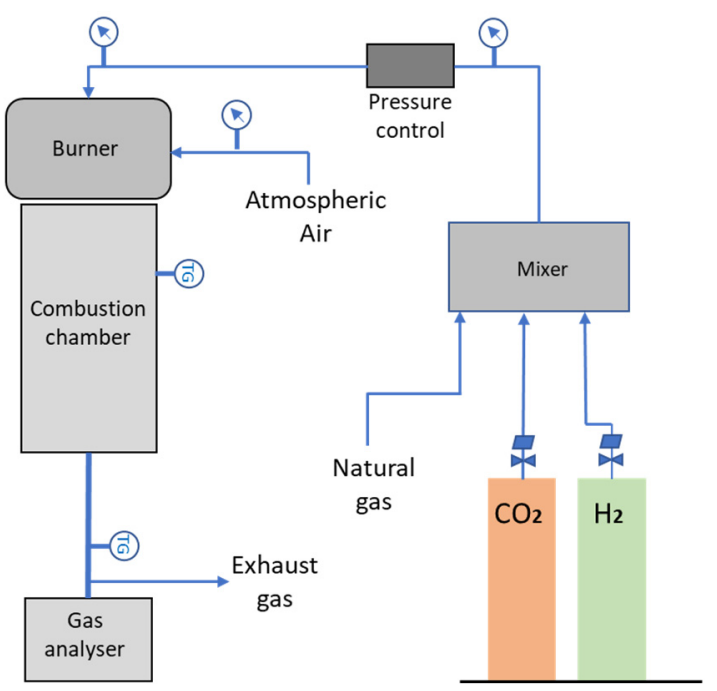

(a)

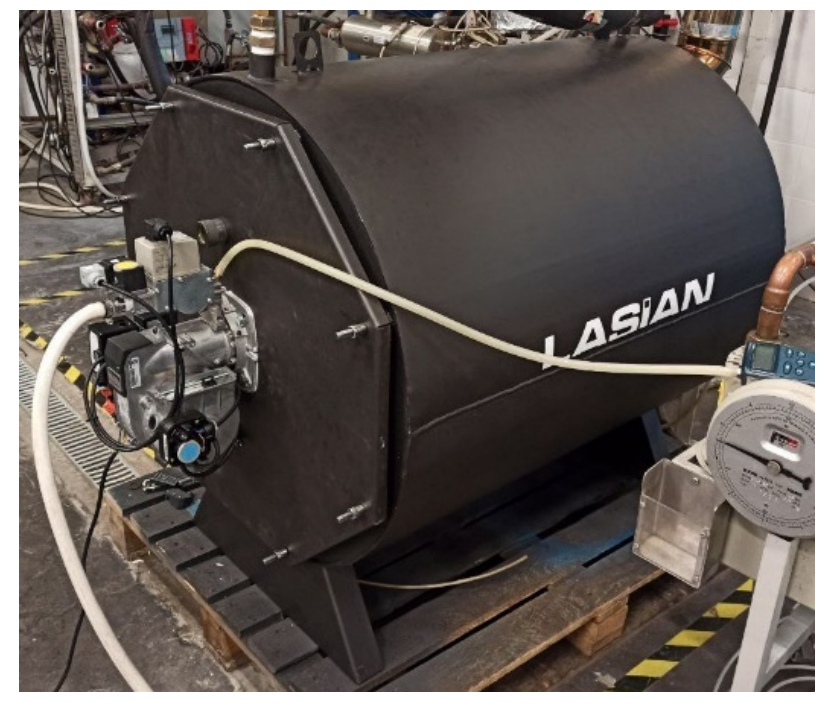

(b)

Figure 2. Combustion system setup: (a) setup outline; (b) burner and combustion chamber tested.

The experimental method is designed for data collection. First, the blend of gases is set by the apertures of the mass controllers. Once the mixture is set, combustion is started. After the first $5 \mathrm{~min}$ of combustion, the concentration data of the exhaust gas stream are registered. During these minutes, the combustion stability is also analyzed. Finally, after $10 \mathrm{~min}$ of combustion, the maximum temperature values are measured, and the fluctuations are recorded.

\subsection{Fuel and Oxidant Properties \\ 2.3.1. Composition}

According to the Spanish National Commission of Markets and Competition (CNMC), most of the gas consumed in Spain comes from Argelia and the United States [42]. Thus, the average composition of the natural gas used for this study can be approximated, as shown in Table 1.

Table 1. Natural gas composition and standard biogas composition (mole percent).

\begin{tabular}{cccc}
\hline Natural Gas & $(\mathbf{\%}) \mathbf{V o l}$ & Biogas & (\%) Vol \\
\hline Methane & 87.9 & Methane & 67 \\
Ethane & 8.5 & Carbon dioxide & 27 \\
Propane & 2 & Hydrogen & 1 \\
Butane & 0.7 & Nitrogen & 4.7 \\
& & Carbon monoxide & 0.1 \\
& & Oxygen & 0.1 \\
& & H2S & 0.1 \\
\hline
\end{tabular}




\subsubsection{Heating Value}

The main properties of gaseous fuels include the Wobbe Index, the heating value and the interchangeability [37]. The heating value is defined as the amount of heat released in the combustion reaction per unit of mass or volume and is closely related to fuel kinetics and adiabatic flame temperature. The heating value of a gas mixture is easily approximated when the molar fraction of each component is known. According to the bibliographical data, Figure 3 compares the heating value of standard biogas, natural gas (Table 1) and the three different biogases under study (BG50, BG60 and BG70), enriched with different percentages of hydrogen [37].

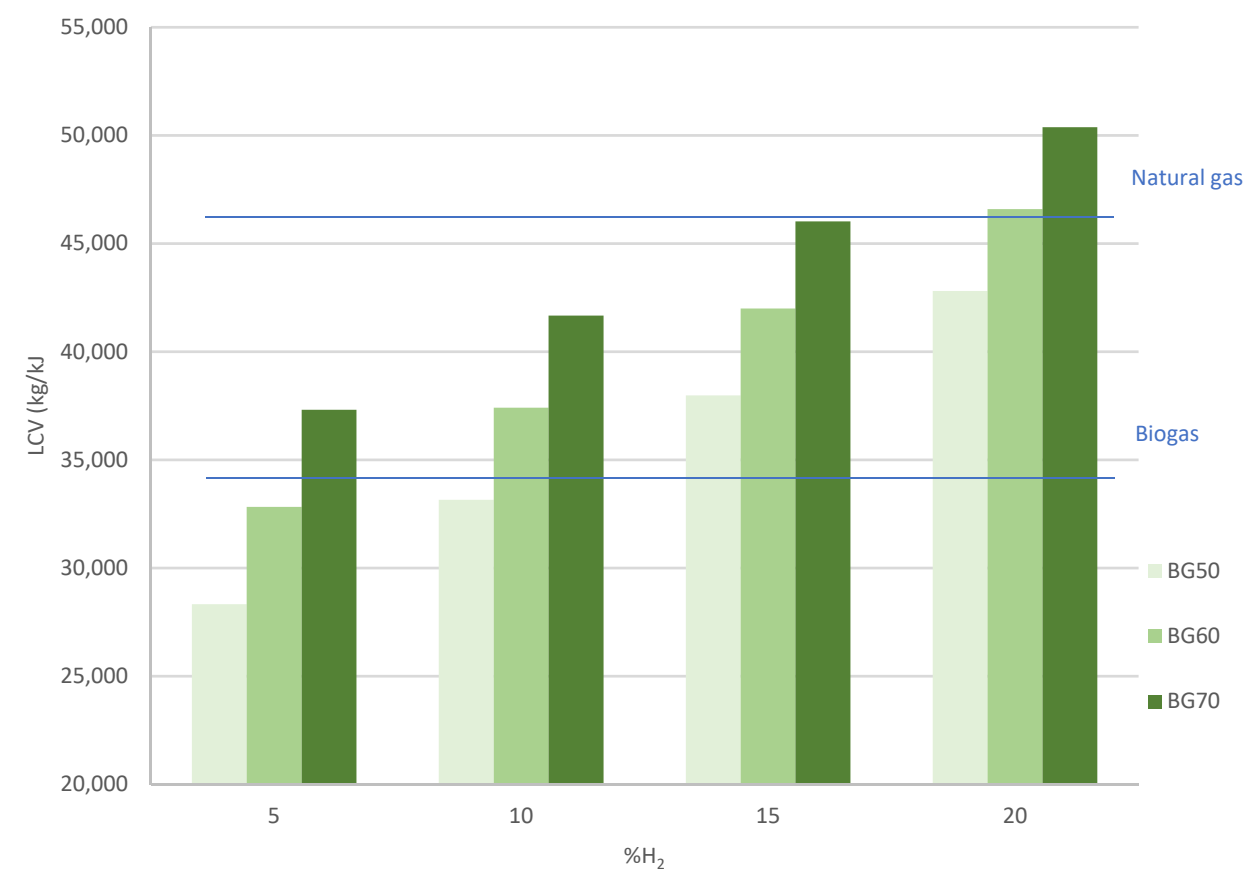

Figure 3. Heating value comparison of BG50, BG60 and BG70, depending on hydrogen content.

The heating value of standard biogas and natural gas (Table 1) remains constant in Figure 3 . The heating value of the blends increases almost linearly when biogas is enriched with hydrogen from $5 \%$ to $20 \%$. Previous experimental researches agree with both the increasing trend and other combustion parameters, such as the increase in radical $\mathrm{H}+$ in the combustion reactions and the laminar burning velocity $[35,43]$. Depending on the $\mathrm{CO}_{2}$ content, the quantity of needed hydrogen to improve the heating value varies. According to Figure 3 and theoretical calculations, while rich biogas needs a $15 \%$ of $\mathrm{H}_{2}$ to reach the heating value of natural gas, poor biogas needs more than $25 \%$ of $\mathrm{H}_{2}$.

\subsubsection{Wobbe Index}

The Wobbe Index is the main indicator of the interchangeability of fuel gases. It is defined as the volumetric value of the heating value at the specified reference conditions divided by the square root of the relative density at the same specified reference measurement conditions. Therefore, two gases with different heating values and densities can produce similar heating loads if they have a similar Wobbe Index value. Figure 4 plots the Wobbe Index results, according to the theoretical method described in the standard EN ISO 6976 [44]. As expected, the Wobbe Index lowers as carbon dioxide is blended into natural gas (Figure 4a). However, for constant carbon dioxide content, the addition of hydrogen increases the Wobbe Index, though more moderately than expected. It is precisely the relative density of hydrogen that smooths the increase in the Wobbe Index. By increasing the hydrogen content by $25 \%$, the Wobbe Index of BG50 improves by $3.4 \%$, while BG60 and BG70 perceive a rise of $7.75 \%$ and $9.77 \%$, respectively. Considering the typical Wobbe 
Index range of natural gas, which is between $39.1 \mathrm{MJ} / \mathrm{m}^{3}$ and $54.8 \mathrm{MJ} / \mathrm{m}^{3}$ [45], not even BG70 reaches the minimum value. The ideal condition to replace natural gas for biogas in a conventional combustion device is to assure the same heating value and Wobbe Index. The results plotted in Figure 4a reflect that $\mathrm{CO}_{2}$ addition to natural gas drastically reduces the Wobbe Index. Since the addition of hydrogen implied an increase in the calorific value of the mixture that exceeded the calorific value of natural gas, a similar trend was expected for the Wobbe Index. However, Figure $4 \mathrm{~b}$ shows that the biogas-hydrogen mixtures considered in this study do not reach the minimum value for natural gas.

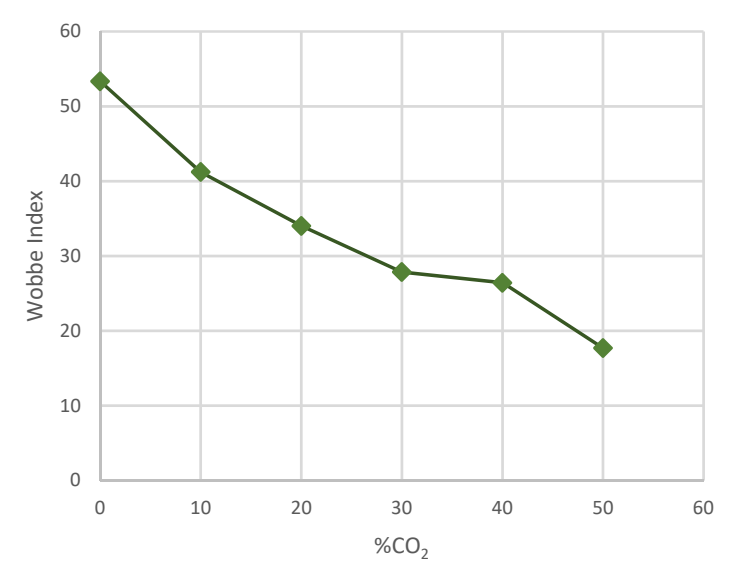

(a)

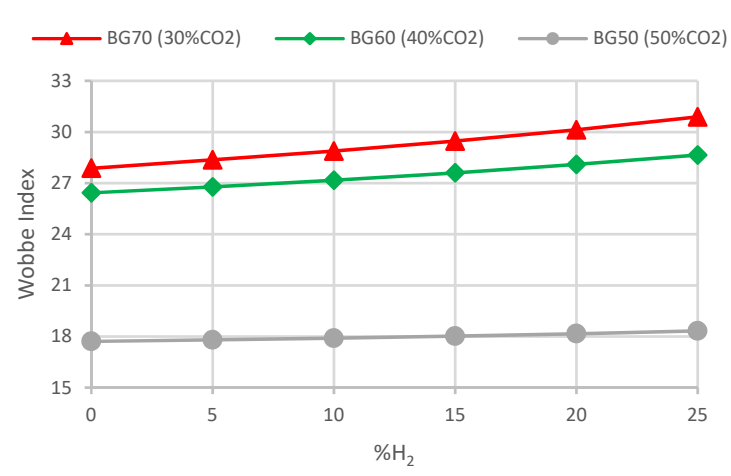

(b)

Figure 4. Wobbe Index analysis of biogas and biogas-hydrogen mixtures: (a) influence of $\mathrm{CO}_{2}$ addition to natural gas Wobbe Index; (b) influence of hydrogen addition to Wobbe Index.

\subsection{Simulation}

In order to delimit the optimal working conditions, the temperature parameters proposed in this study are simulated using AspenPlus@ software. The simulation is carried out through a simple methodology in which the Gibbs free energy is minimized. In addition, the thermal equilibrium conditions between the phases (liquid/gas) are established. In this way, the main reactions of the process are determined, basing the selection on the probability of their occurrence. The sensitivity analysis of the parameters is presented in the results section.

\section{Results and Discussion}

\subsection{Temperature Analysis}

\subsubsection{Simulation Results}

The combustion temperature can be measured directly from the exhaust or through the refrigeration water, both methods being an indirect measurement of efficiency. However, the temperature analysis may differ depending on the thermocouple position inside the experimental setup. The exhaust gas temperature is a valuable parameter because the obtained results can later be escalated to energy generators through numerical or software simulations. The temperature analysis is first carried out simulating the combustion system conditions, and then by experimental combustion tests.

Thus, the optimal working conditions are first evaluated by software simulation with the AspenPlus( program. The optimization criteria consider two main parameters. The first one is the maximum combustion efficiency expressed as the minimum $\mathrm{CO}$ content in the exhaust gas compared to $\mathrm{CO}_{2}$ generation.

$$
\eta_{-} \mathrm{comb}=\mathrm{CO}_{2} \text { out } /\left(\mathrm{COout}+\mathrm{CO}_{2} \text { out }\right)
$$


The second one corresponds to hydrogen consumption.

$$
\mathrm{H}_{2} \text { cons }=\left(\mathrm{H}_{2} \text { in }-\mathrm{H}_{2} \text { burnt-out }\right) / \mathrm{H}_{2} \text { in }
$$

The range of variables used for the simulation are shown in Table 2.

Table 2. Set variables.

\begin{tabular}{cc}
\hline Parameter & Range \\
\hline $\mathrm{H}_{2}$ mass fraction & $0-0.25$ \\
$\mathrm{CO}_{2}$ mass fraction & $0.3-0.6$ \\
Ratio air/fuel & $22-44$ \\
\hline
\end{tabular}

To evaluate the flame temperature and chamber duty, the parameters range of Table 2 is established. Figure 5 represents the initial results, where it can be seen that higher temperatures produce higher powers. However, higher temperatures do not correspond to the optimal conditions as the highest temperatures reach $2000{ }^{\circ} \mathrm{C}$, overpassing the material limitations. Regarding hydrogen addition, higher efficiencies are obtained between 0 and $40 \%$ of hydrogen consumption. In these conditions, the combustion efficiency would be very low, the hydrogen would not be consumed, and, thus, it would be expelled almost completely out of the chimney.

Temperature $\left[{ }^{\circ} \mathrm{C}\right]$

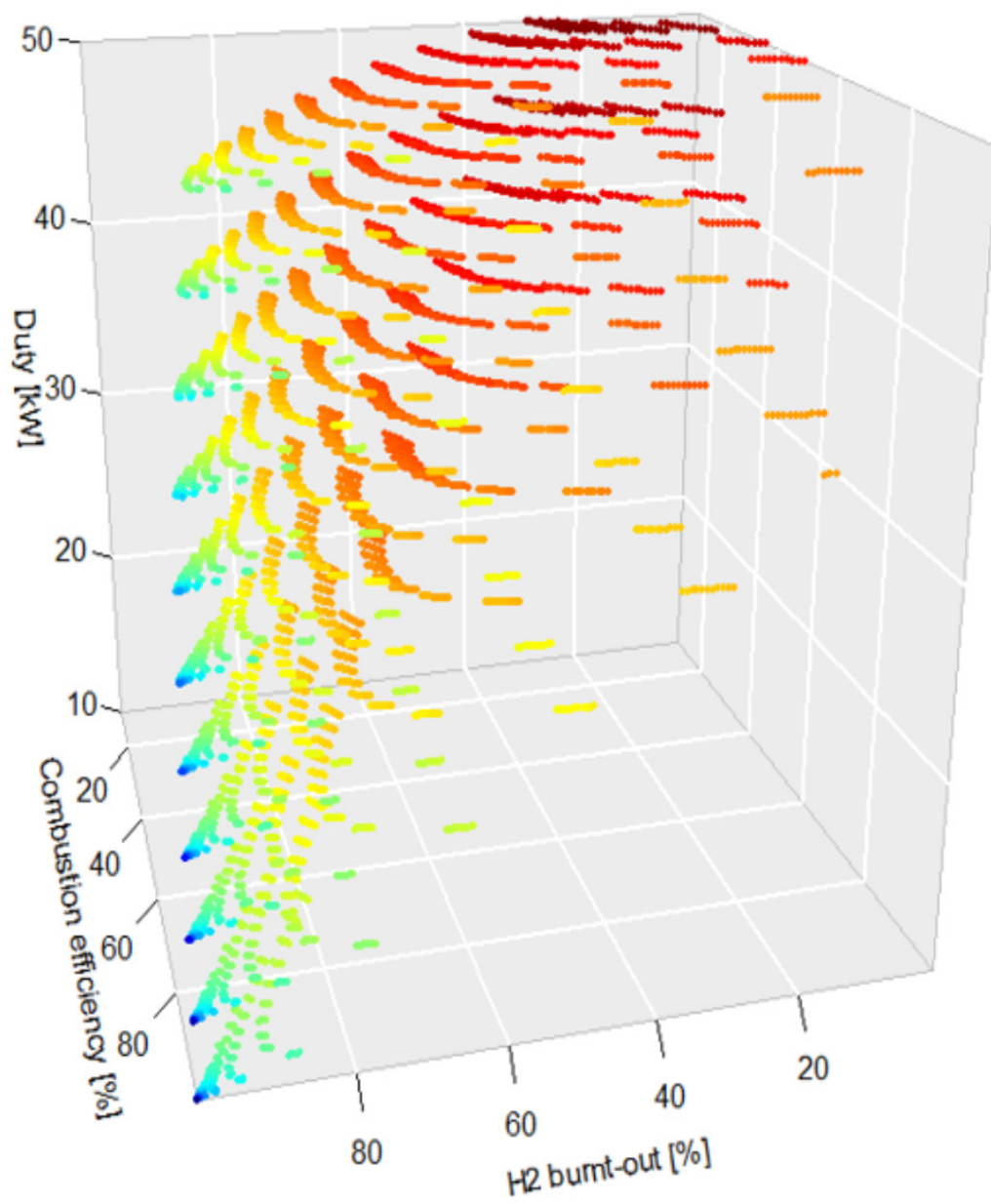

Figure 5. Initial conditions of the sensitivity analysis. 
Considering that the estimated power for natural gas in the simulation is $30 \mathrm{~kW}$, all the values under this threshold need to be disposed of to guarantee that the system does not lose power. Assuming the abovementioned premise, the simulation is limited to ensure a hydrogen consumption higher than $95 \%$ and a power combustion higher than $30 \mathrm{~kW}$. Figure 6 shows the bounded results where the optimal conditions take place when the combustion efficiency is between 40 and $50 \mathrm{~kW}$ and hydrogen consumption is about $95-97 \%$, reaching flame temperatures between 2000 and $2200{ }^{\circ} \mathrm{C}$.

\section{Molar ratio air/fuel}
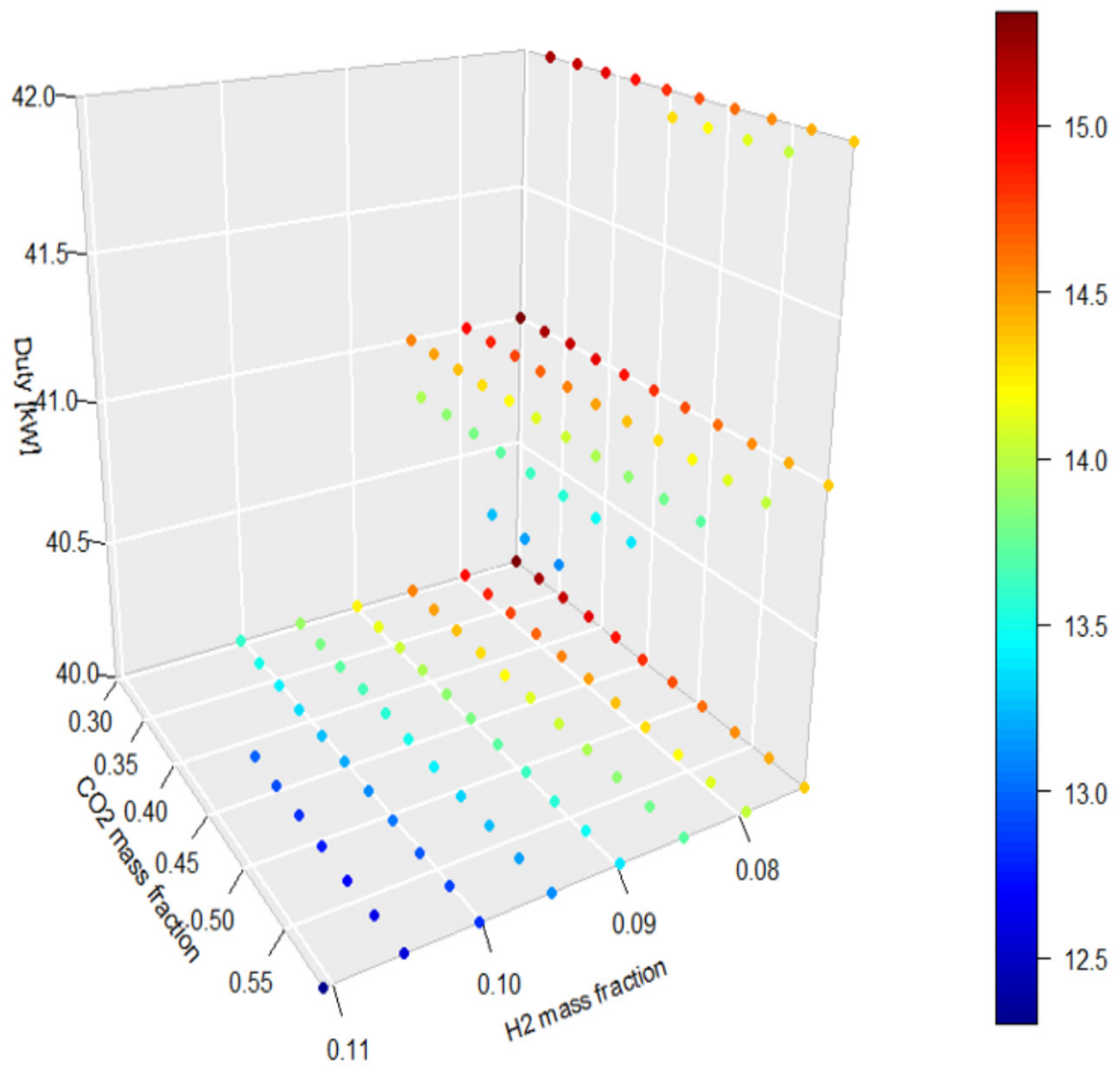

Figure 6. Optimal operation conditions.

Figure 7 shows the results after the application of the limitations stated in Figure 6. The greater duties occur when the air/fuel molar ratios are set between 12 and 16. After the simulation results, the optimal enrichment percentage of hydrogen can be defined as between 8 and $12 \%$. On the other hand, the increase in $\mathrm{CO}_{2}$ content decreases the duty, as expected. 


\section{Temperature $\left[{ }^{\circ} \mathrm{C}\right]$}

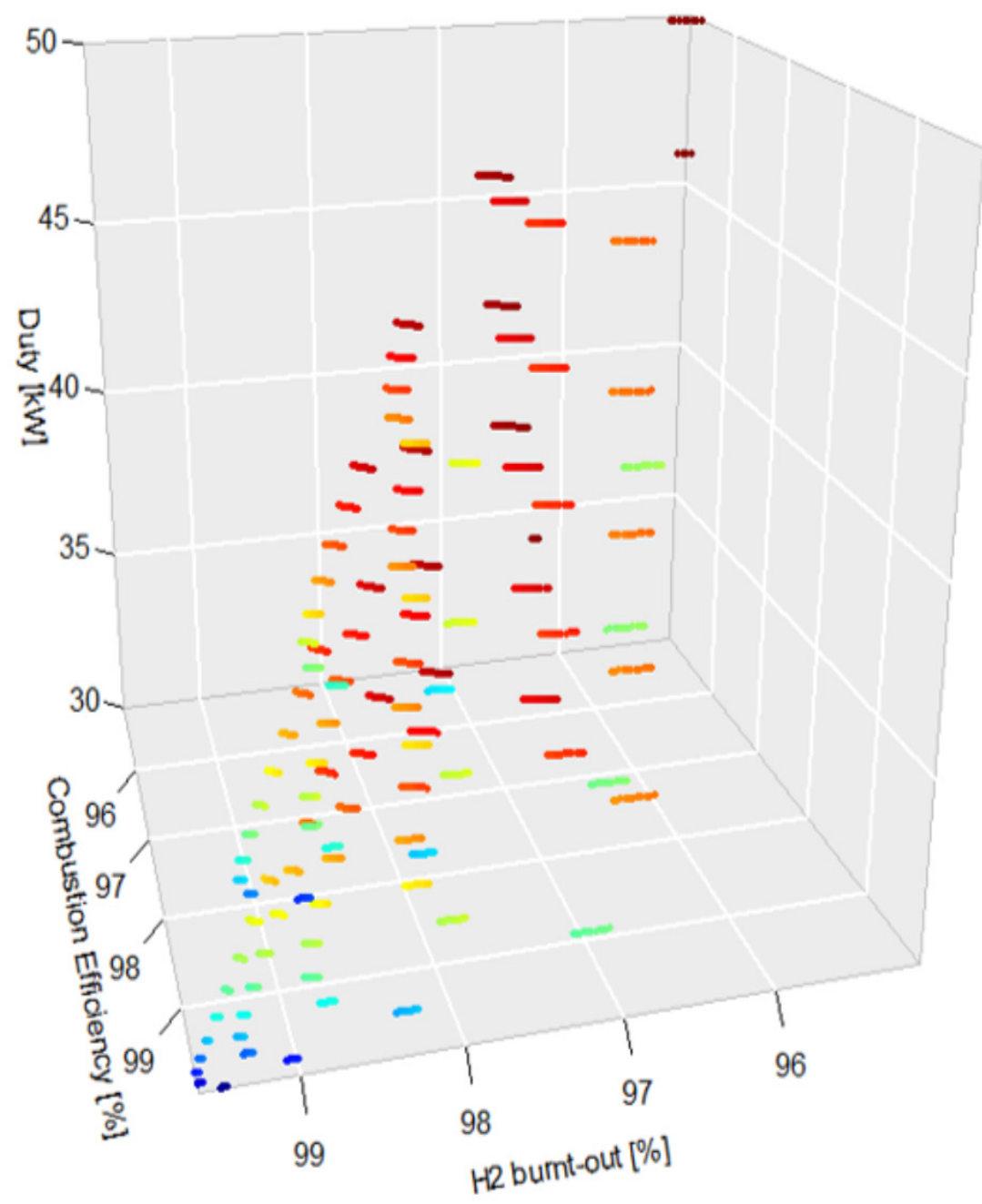

Figure 7. Operation variables results.

\subsubsection{Experimental Results}

The use of conventional natural gas burners limits the $\mathrm{CO}_{2}$ range. Thus, it is essential to find the threshold value of $\mathrm{CO}_{2}$ content when the conventional burner does not ignite. Figure 8 shows, on the left axis, the temperature decrease registered during the tests. It can be noticed that as the $\mathrm{CO}_{2}$ percentage increases, the exhaust gas temperature drops considerably. When the ignition succeeds at $40 \%$ of $\mathrm{CO}_{2}$, the temperature registered has strong fluctuations, complicating the data acquisition. The burner does not properly ignite with $\mathrm{CO}_{2}$ percentages higher than $40 \%$. The oxidant and fuel consumption remain constant during all the tests; consequently, the lambda also remains constant. Both parameters directly affect the lambda, which is the optimal fuel/oxidant proportion to ensure complete combustion. According to Regulation (EU) 2016/426 [46], conventional combustion systems work with a combustion lambda of around 1.3, assuring a $20 \%$ of oversupplying air. Figure 8, on the right axis, confirms the effect of $\mathrm{CO}_{2}$ addition, cutting down the combustion quality. This is explained, as $\mathrm{CO}_{2}$ reduces the fuel flow entering the burner. 


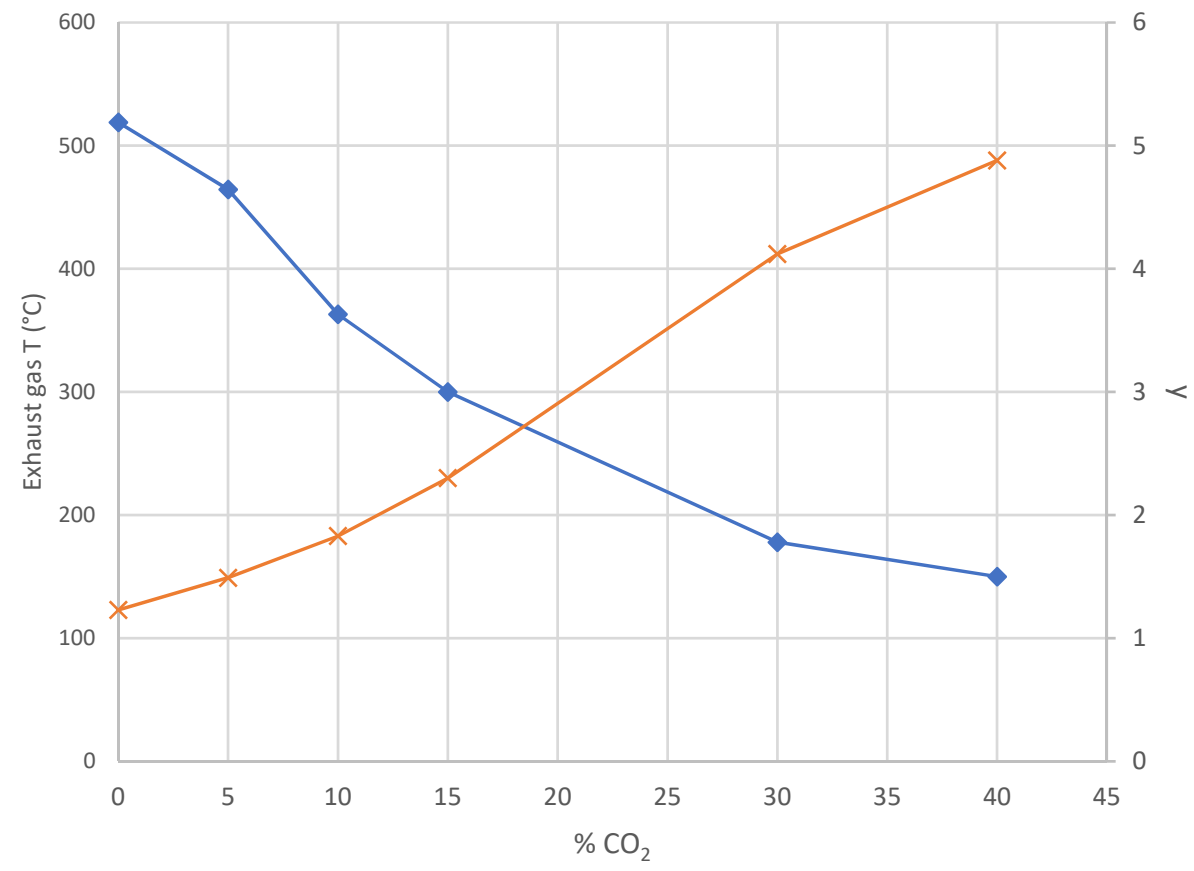

Figure 8. Effect of $\mathrm{CO}_{2}$ addition to the exhaust gas temperature and the combustion lambda.

The burner operation range is then set between 0 and $40 \%$ of the $\mathrm{CO}_{2}$ content. At $40 \%$ of $\mathrm{CO}_{2}$, the combustion is remarkably weak and unstable. Normally, the carbon dioxide content is found to be between $30 \%$ and $50 \%$ before the treatment is upgraded. Hence, it is interesting to test BG50, BG60, and BG70 with different hydrogen percentages. BG50 cannot ignite in the burner, so the test intends to demonstrate the ability of hydrogen to stabilize the combustion flame and to carry out the combustion of low heating value fuels.

Despite the simulation results stating the possibility to overcome the temperatures of natural gas, the experimental results plot a different tendency (Figure 9). In every case, the temperature increases at the same time that the hydrogen percentage does. By adding $5 \%$ of hydrogen, the temperature rises by approximately $80 \%$ for BG70 and $65 \%$ for BG60. When the mixture contains more than $10 \%$ of hydrogen, temperatures rise more slowly until they reach 20 and $25 \%$ of hydrogen, where the temperature increment is stabilized in $5 \%$. If the biogas and natural gas combustion temperatures are compared, it can be noticed that biogas shows temperatures $70 \%$ lower than that of natural gas, which is an important negative impact on the combustion behavior. This temperature decrease is translated into a significant decrease in efficiency and, consequently, a lower energy efficiency. Hydrogen addition partially reverses this trend and allows biogas to be burned more efficiently, although none of the tested blends reaches the values obtained from natural gas.

Figure 9 plots the maximum temperature value for each point. However, large temperature fluctuations are observed during the tests. For mixtures that do not contain hydrogen, variations of up to $85^{\circ} \mathrm{C}$ are observed in BG70, with fluctuations of up to $100{ }^{\circ} \mathrm{C}$ being recorded for BG60. This effect is observed mainly in the first minutes of combustion. As hydrogen is added, the fluctuations decrease considerably. The improvement in register stability is particularly noticeable when $5 \%$ hydrogen is added, as the recorded variations decrease up to $20-35^{\circ} \mathrm{C}$. From $10 \%$ onwards, a smaller decrease in fluctuations is experienced, although the combustion temperature increases as discussed above. This effect is directly related to the stability of the flame, which is impaired by the increase in $\mathrm{CO}_{2}$ in the mixture.

The results can vary from the bibliographic data, as carbon dioxide and hydrogen additions to methane or natural gas have been normally tested in laboratory devices or low-power appliances, focusing mainly on flame stability [37]. 


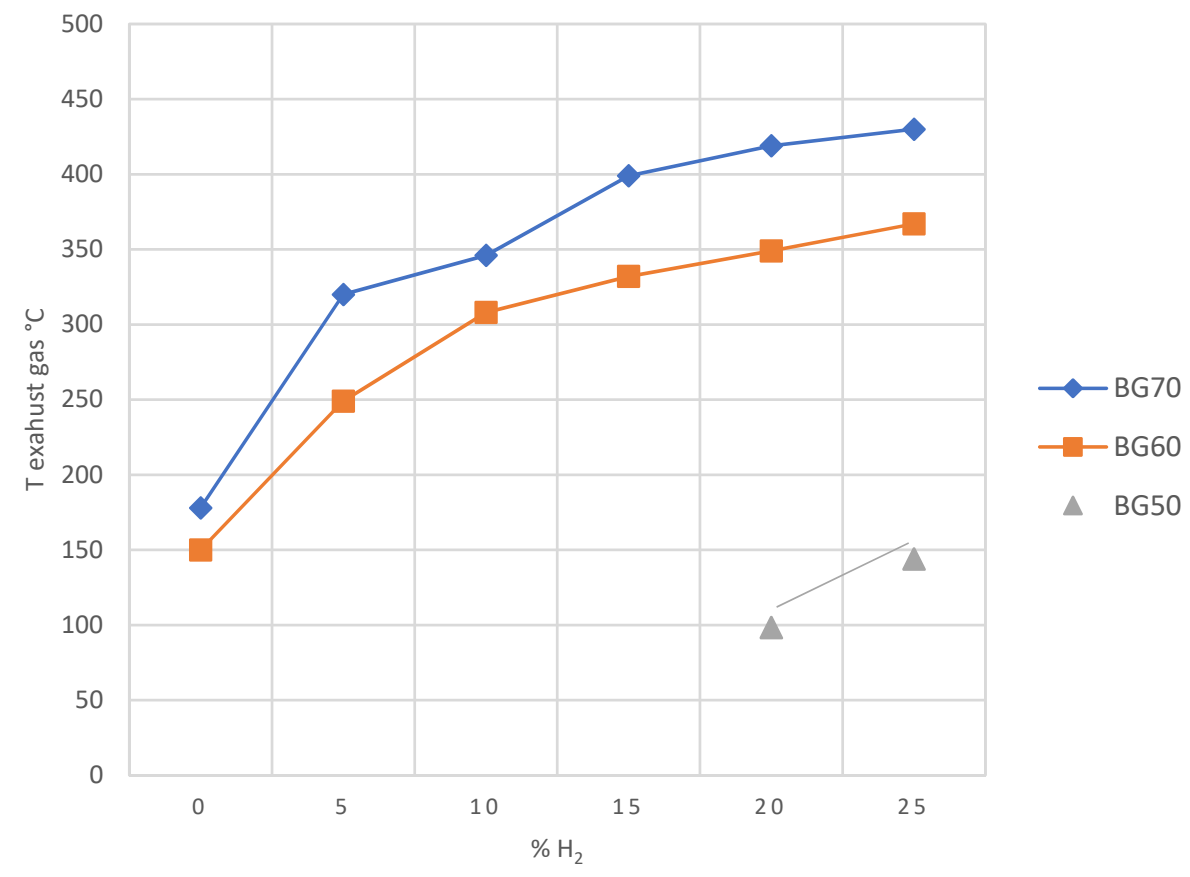

Figure 9. Exhaust gas stream temperature.

\subsection{Combustion Behavior}

\subsubsection{Combustion Stability}

Fuel composition variability is a strong limitation in biogas combustion. Biogas composition varies depending on the waste characteristics; even if they are the same waste, it can vary depending on the season, humidity, storage, etc. Hydrogen addition also affects fuel variability and can worsen it at high concentrations [47]. Fuel variability has a strong effect on flame speed fluctuation, causing instability in combustion. Kai Zhang and Xi Jiang demonstrated that a high hydrogen content reduces laminar flame speed variance and has a significant impact on methane reaction [12]. The hydrogen content causes a suppression of carbon dioxide contribution. They revealed a second finding regarding the adiabatic flame temperature, as high hydrogen content reduces the effect of methane and increases the carbon dioxide contribution. Consequently, hydrogen addition in biogas decreases the practical fuel variability and flame fluctuation. However, when methane content exceeds $70 \%$ in biogas-hydrogen fuel, a high hydrogen content can promote flame fluctuation. The aim of this study is to propitiate combustion stability in a conventional burner, so the hydrogen content does not surpass $25 \%$.

During the tests, the burner behavior was observed through the stability electronic control incorporated in the burner. Residential or industrial burners are electronically controlled systems designed to avoid safety hazards. Thus, they are rigid systems, prepared to work in specific operational conditions. Every single change affects the combustion and normally produces ignition failure. Figure 10 represents the stability map registered during the tests. The stability map is divided into three regions, where the red area represents poor combustion, the yellow area represents unstable combustion, and the green area represents stable combustion. 


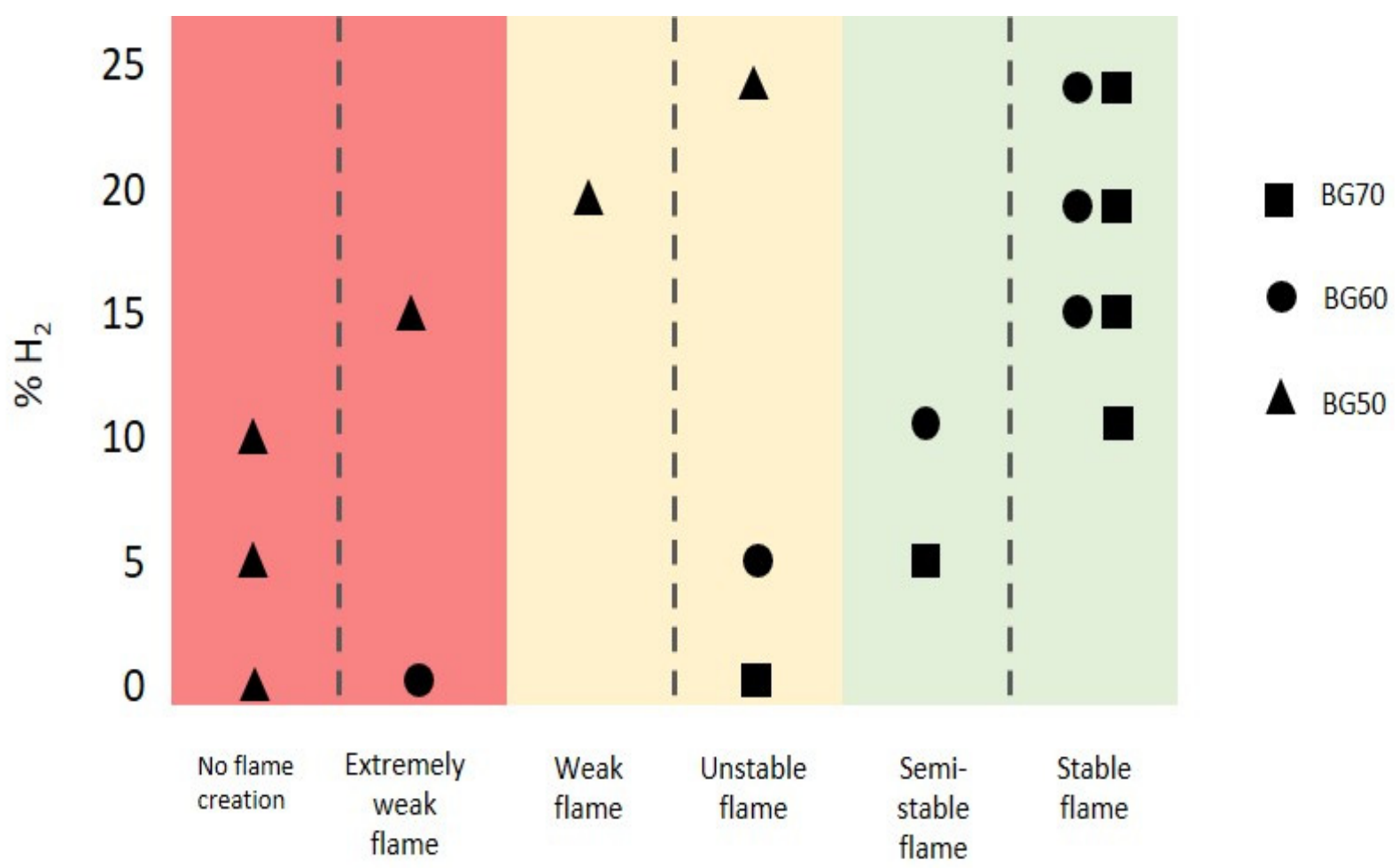

Figure 10. Stability map.

The ignition testing results coincide with other research works carried out with laboratory devices $[13,18,34]$. The stability map reveals that pure biogas combustion is unstable in every case, and when the $\mathrm{CO}_{2}$ content is $50 \%$, the flame does not exist. As observed in the temperature analysis, a reduced amount of hydrogen considerably improves combustion stability. Even registering large fluctuations in the combustion, the conventional burner can maintain the flame for every experiment tested, except for BG50, which requires $15 \%$ hydrogen to ignite but $20 \%$ to maintain a weak flame. In accordance with other laboratory combustion devices, the addition of hydrogen improves the combustion behavior. This tendency complies with the temperature results [48]. Hydrogen has a wider flammability range and a higher heating value than methane and, hence, the hydrogen addition extends the flammability limits and, consequently, flame stability.

\subsubsection{Exhaust Gas Analysis}

Unlike laboratory devices designed to evaluate flame behavior, the combustion chamber geometry also affects the combustion behavior [49]. Spatial distribution is essential to boost the energy transmission to the carried fluid or to propitiate the greater harnessing of the exhaust enthalpy. The thermic phenomenon occurring inside the combustion chamber can diverge from bibliographic results using smaller devices. Combustion behavior is also evaluated from the exhaust gas concentration variations point of view.

According to Zhilong Wei et al., $\mathrm{O}_{2}$ emissions decrease while the carbon dioxide proportion increases [47]. The carbon dioxide content is reduced while $\mathrm{H}_{2}$ is added, as hydrogen dilutes the gas mixture. This effect is also observed in Figure 11b, where the percentage of $\mathrm{O}_{2}$ contained in the exhaust is reduced by around $37 \%$ from 0 to $25 \%$ of hydrogen for BG70 and BG70. From a practical point of view, the lower the $\mathrm{O}_{2}$ content in the exhaust, the more complete the reaction. Typically, the $\mathrm{O}_{2}$ content in the chimney is about 3\% [50]. Figure 11b shows a singular point, which coincides with an increase higher than expected in the $\mathrm{CO}_{2}$ emissions. At this point $\left(15 \% \mathrm{H}_{2}\right)$, lambda does continue with the expected trend. Hence, since fuel and comburent consumption remain constant during all the tests and their repetitions, this can be considered an anomalous point. 


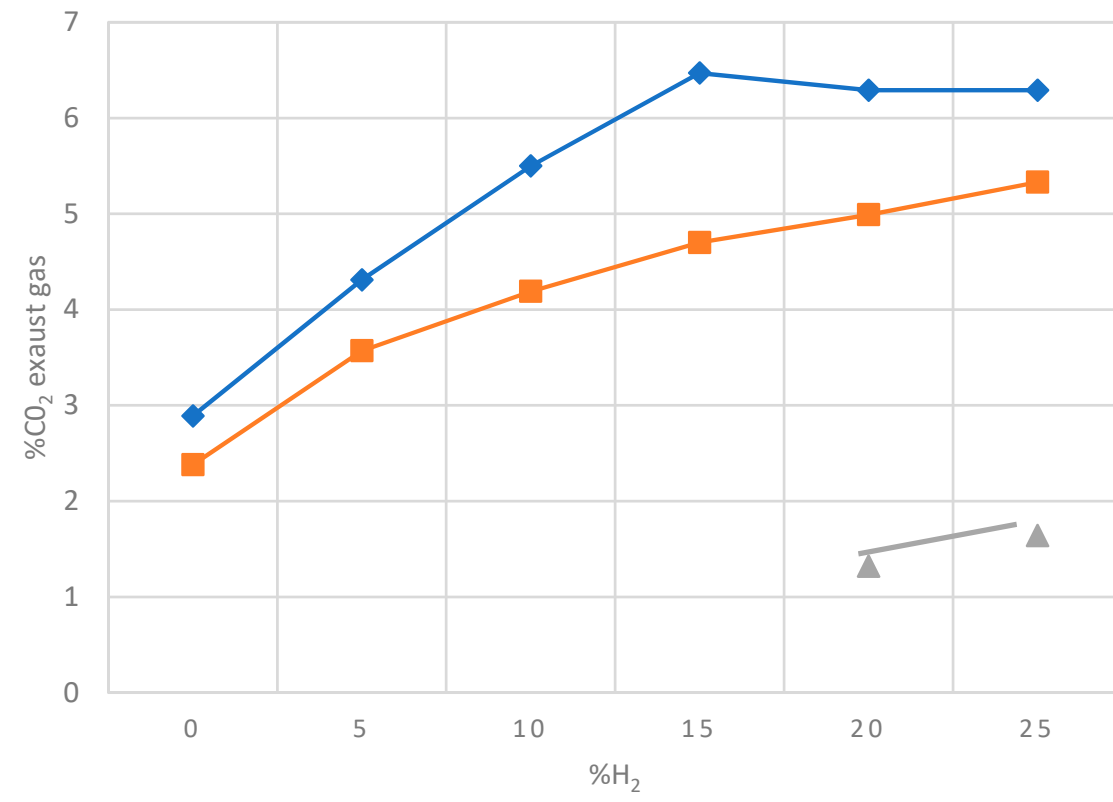

$\multimap B$ BG70

-BG60

$\triangle$ BG50

(a)

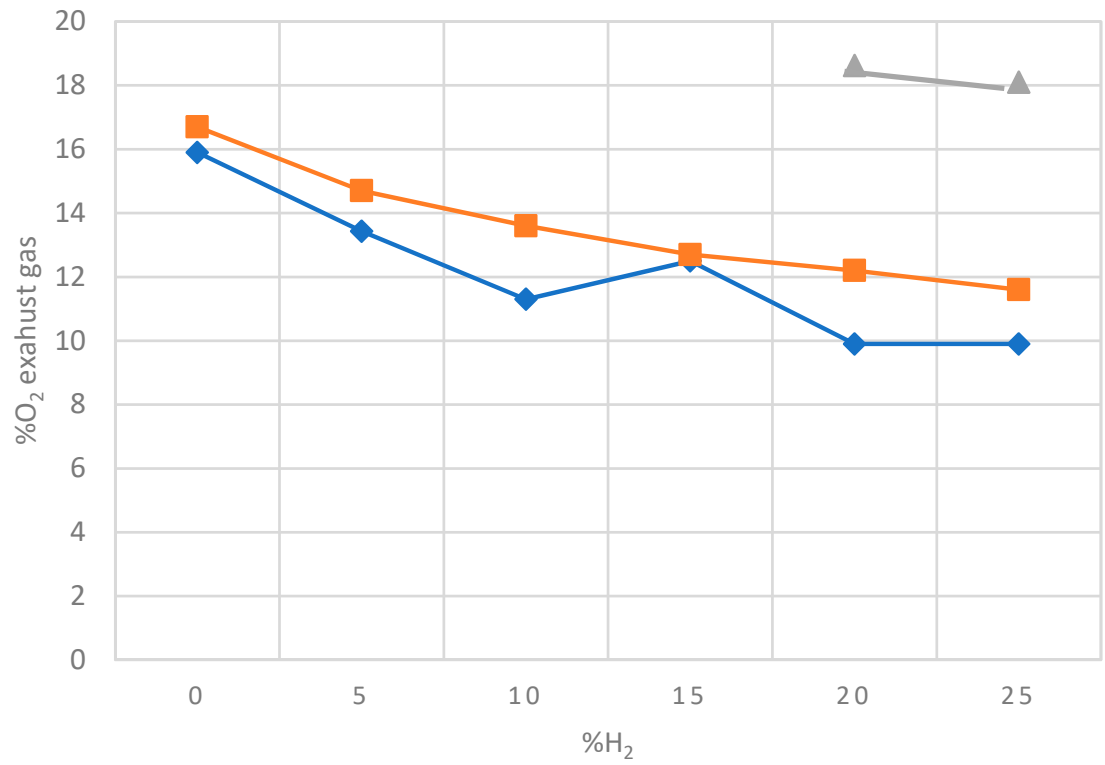

$\smile$ BG70

- BG60

- BG50

(b)

Figure 11. Cont. 


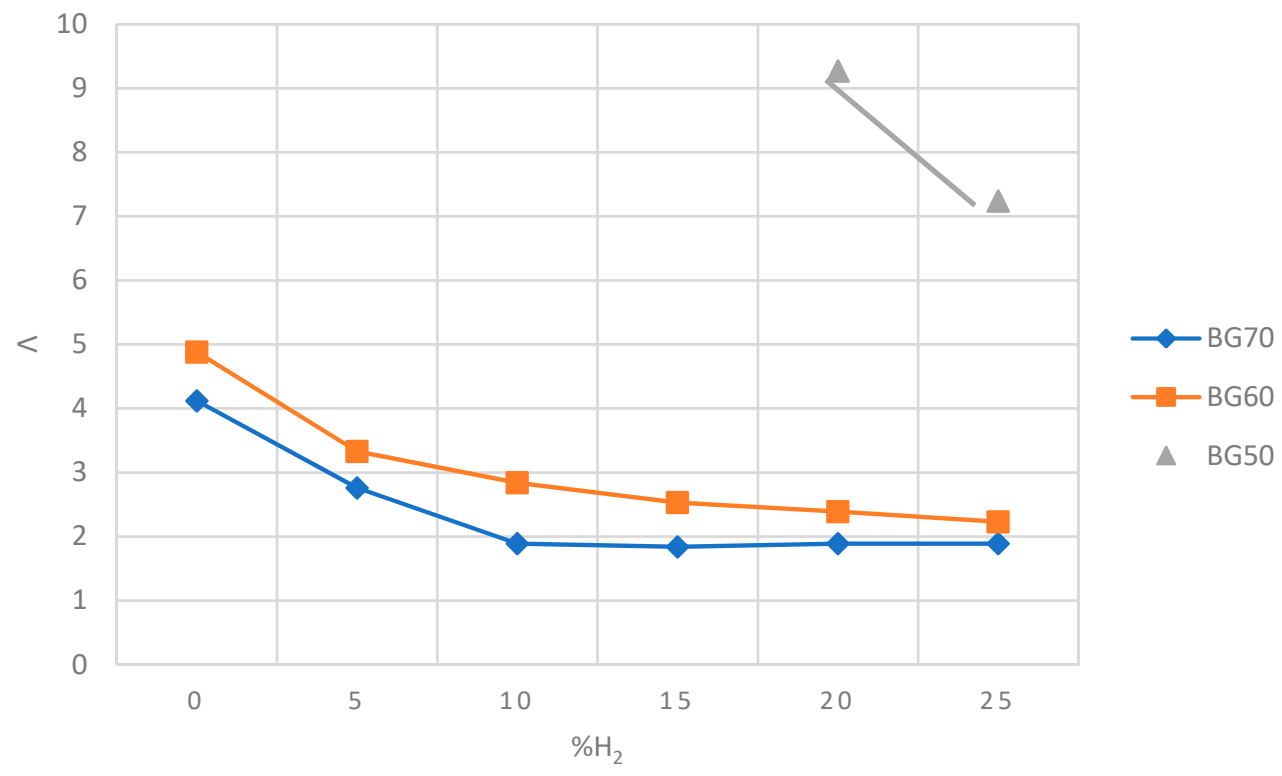

(c)

Figure 11. Exhaust gas variations due to hydrogen addition: (a) influence of $\mathrm{O}_{2}$ addition to $\mathrm{CO}_{2}$ emissions; (b) influence of $\mathrm{O}_{2}$ addition to $\mathrm{O}_{2}$ emissions; (c) influence of $\mathrm{O}_{2}$ addition to combustion lambda.

The connection between $\mathrm{O}_{2}$ emissions and $\mathrm{CO}_{2}$ emissions is explained through fuel consumption. The oxidant flow remains constant on every test. A reduction in the $\mathrm{O}_{2}$ percentage necessarily implies an improvement of the combustion behavior. Hydrogen displaces the carbon dioxide content in the blend and increases the heating value of the biogas, increasing, too, the $\mathrm{O}_{2}$ consumption. Next to this, the percentage of $\mathrm{CO}_{2}$ increases as the combustion reaction kinetics enhances. In Figure 11 a, the $\mathrm{CO}_{2}$ content registered for BGA60 and BG70 enriched with $12 \%$ of hydrogen is 5.33 and 6.29 , respectively, which is still far from the 9.06 registered from natural gas. The lambda tendency confirms the improvement on combustion behavior related to the hydrogen addition. However, as it is observed with $\mathrm{CO}_{2}$ and $\mathrm{O}_{2}$ emissions, the difference between 20 and $25 \%$ of hydrogen addition is practically insignificant, observing a flattening of the curve. BG50 does not fail to ignite when it contains less than $15 \%$ of hydrogen, and, at this point the flame is extremely weak, hindering the data acquisition. Consequently, Figure 11a-c just reflects the points of BG50, where the combustion can be maintained in time. The tendency is similar to BG60 and BG70, but the limited data available prevent the correct evaluation of hydrogen addition to BG50.

After the results evaluation, the expected trend, also observed by other authors in the literature $[13,32,47]$, is confirmed. The combustion characteristics of biogas can be significantly improved by the addition of small amounts of hydrogen. In this study, this effect was observed on a conventional industrial burner capable of working up to $100 \mathrm{~kW}$. Unlike smaller equipment, these conventional systems are built to operate under stable operating conditions, so variations in the fuel seriously affect the combustion of the burner. In this case, it was confirmed that working with lean biogas containing $\mathrm{CO}_{2}$ concentrations above $40 \%$ is not possible. The combustion is very unstable and leads to safety failures and equipment shutdown. However, for the BG60 and BG70, the addition of hydrogen stabilizes combustion and allows the burner to operate without failure for long periods of time. This effect is especially remarkable for hydrogen enrichment percentages between 5 and $10 \%$, as it is precisely at these proportions that the greatest percentage improvement is obtained. It was also verified that the burner's own safety systems are not affected by the change, acting correctly. These systems are very sensitive to variations in the fuel-oxidant mixture since the flame detection circuit works by ionization, the richness of the fuel mixture being an essential parameter. 


\section{Conclusions}

The results obtained provide relevant conclusions concerning the combustion of the enriched biogas, which are presented below. The experimental data confirmed the difficulty of burning biogas in conventional systems. Its low calorific value and the unfavorable effect of $\mathrm{CO}_{2}$ increase the flame instability and, therefore, the combustion quality decrease. When biogas contains more than $40 \%$ of $\mathrm{CO}_{2}$, an ignition failure occurs in the burner. Therefore, BG50 cannot be tested in this equipment in its pure state. The combustion of BG60 and BG70 was poor and unstable, although it was possible to burn it directly in the burner.

As expected, the addition of hydrogen considerably improved the combustion properties of biogas, even in combustion systems of this power capacity. The main increase occurred by adding $5 \%$ hydrogen, as the fuel exhaust temperature rose by $80 \%$ for BG70 and $65 \%$ for BG60. The addition of $10 \%$ also had consequential effects; however, the improvement trend flattened out for addition percentages between $20 \%$ and $25 \%$.

The poor combustion behavior was confirmed by the study of $\mathrm{O}_{2}$ and $\mathrm{CO}_{2}$ emissions, as well as the combustion lambda. Although the values obtained after enriching the mixtures with hydrogen did not reach the ones recorded from natural gas, the improvement in combustion characteristics was remarkable. A temperature increase may have a negative effect on NOx generation, so it would be interesting to look further into this aspect in future research.

Based on the results of this study, it can be concluded that biogas is not a suitable fuel for natural gas high-power heating combustion systems. However, optimal operating conditions are established when biogas is enriched with hydrogen. These conditions are obtained for hydrogen percentages between 5 and $10 \%$, provided that the carbon dioxide content is higher than $60 \%$.

The results importance of this study lies in the possibility of taking advantage of conventional combustion systems to burn alternative fuels, such as biogas. Thanks to the addition of small amounts of hydrogen, it is possible to work with equipment designed to consume natural gas. This can be an advantage for today's industry, which must invest heavily to be able to meet the environmental restrictions that will continue to increase over the years.

Author Contributions: Conceptualization-I.A. and M.F.O.; data curation-I.A.; formal analysisM.J.G.-M. and D.B.; funding acquisition-M.F.O., I.A. and B.L.; investigation-B.C. and I.A.; methodology-I.A.; experimentation-I.A. and J.L.L.; project administration-M.F.O. and I.A.; resources-D.B., M.J.G.-M., J.G.-T., M.F.O., B.L. and J.L.L.; software-M.F.O.; supervision-J.L.L.; validation-I.A. and B.C.; visualization-I.A.; roles/writing—original draft, B.C. and I.A.; writingreview and editing, M.F.O. and D.B. All authors have read and agreed to the published version of the manuscript.

Funding: This research was funded by Fundación Iberdrola, under project grant "Smart BioH2".

Acknowledgments: The authors would like to thank the Fundación Iberdrola for supporting this research under project grant "Smart BioH2". We would also like to thank Rocío Sánchez Ramos for her contribution as a translator and editor of the text.

Conflicts of Interest: The authors declare no conflict of interest.

\section{References}

1. Al Baroudi, H.; Awoyomi, A.; Patchigolla, K.; Jonnalagadda, K.; Anthony, E. A review of large-scale $\mathrm{CO}_{2}$ shipping and marine emissions management for carbon capture, utilisation and storage. Appl. Energy 2021, 287, 116510. [CrossRef]

2. Neves, S.A.; Marques, A.C.; Patrício, M. Determinants of $\mathrm{CO}_{2}$ emissions in European Union countries: Does environmental regulation reduce environmental pollution? Econ. Anal. Policy 2020, 68, 114-125. [CrossRef]

3. Shah, S.A.A.; Longsheng, C.; Solangi, Y.A.; Ahmad, M.; Ali, S. Energy trilemma based prioritization of waste-to-energy technologies: Implications for post-COVID-19 green economic recovery in Pakistan. J. Clean. Prod. 2021, 284, 124729. [CrossRef]

4. Slorach, P.C.; Stamford, L. Net zero in the heating sector: Technological options and environmental sustainability from now to 2050. Energy Convers. Manag. 2021, 230, 113838. [CrossRef] 
5. Olabi, A.; Wilberforce, T.; Abdelkareem, M.A. Fuel cell application in the automotive industry and future perspective. Energy 2021, 214, 118955. [CrossRef]

6. Desantes, J.; Molina, S.; Novella, R.; Lopez-Juarez, M. Comparative global warming impact and NOX emissions of conventional and hydrogen automotive propulsion systems. Energy Convers. Manag. 2020, 221, 113137. [CrossRef]

7. Pichler, M.; Krenmayr, N.; Schneider, E.; Brand, U. EU industrial policy: Between modernization and transformation of the automotive industry. Environ. Innov. Soc. Transit. 2021, 38, 140-152. [CrossRef]

8. O'Connor, S.; Ehimen, E.; Pillai, S.; Black, A.; Tormey, D.; Bartlett, J. Biogas production from small-scale anaerobic digestion plants on European farms. Renew. Sustain. Energy Rev. 2021, 139, 110580. [CrossRef]

9. Brémond, U.; Bertrandias, A.; Steyer, J.-P.; Bernet, N.; Carrere, H. A vision of European biogas sector development towards 2030: Trends and challenges. J. Clean. Prod. 2021, 287, 125065. [CrossRef]

10. Augelletti, R.; Galli, S.; Gislon, P.; Granati, M.; Monteleone, G.; Murmura, M.A.; Annesini, M.C. Biogas upgrading through CO 2 removal by chemical absorption in an amine organic solution: Physical and technical assessment, simulation and experimental validation. Biomass-Bioenergy 2020, 141, 105729. [CrossRef]

11. Moghaddam, E.; Ahlgren, S.; Hulteberg, C.; Nordberg, Å. Energy balance and global warming potential of biogas-based fuels from a life cycle perspective. Fuel Process. Technol. 2015, 132, 74-82. [CrossRef]

12. Zhang, K.; Jiang, X. An assessment of fuel variability effect on biogas-hydrogen combustion using uncertainty quantification. Int. J. Hydrogen Energy 2018, 43, 12499-12515. [CrossRef]

13. $\mathrm{Hu}, \mathrm{Z} . ; \mathrm{Zhang}$, X. Experimental study on flame stability of biogas / hydrogen combustion. Int. J. Hydrogen Energy 2019, 44, 5607-5614. [CrossRef]

14. de Blasio, C. Processes of Bioethanol Production in Green Energy and Technology; Springer: Cham, Switzerland, 2019; pp. $233-252$.

15. Ferreira, A.F.; Toledo-Cervantes, A.; De Godos, I.; Gouveia, L.; Munõz, R. Life cycle assessment of pilot and real scale photosynthetic biogas upgrading units. Algal Res. 2019, 44, 101668. [CrossRef]

16. Fernández-González, J.; Martín-Pascual, J.; Zamorano, M. Biomethane injection into natural gas network vs composting and biogas production for electricity in Spain: An analysis of key decision factors. Sustain. Cities Soc. 2020, 60, 102242. [CrossRef]

17. Widera, B. Renewable hydrogen implementations for combined energy storage, transportation and stationary applications. Therm. Sci. Eng. Prog. 2020, 16, 100460. [CrossRef]

18. Zhen, H.; Leung, C.W.; Cheung, C.S.; Huang, Z. Combustion characteristic and heating performance of stoichiometric biogashydrogen-air flame. Int. J. Heat Mass Transf. 2016, 92, 807-814. [CrossRef]

19. Zhang, J.; Wang, M.; Xu, S.; Feng, Y. Hydrogen and methane mixture from biomass gasification coupled with catalytic tar reforming, methanation and adsorption enhanced reforming. Fuel Process. Technol. 2019, 192, 147-153. [CrossRef]

20. Hussain, T.; Talibi, M.; Balachandran, R. Investigating the effect of local addition of hydrogen to acoustically excited ethylene and methane flames. Int. J. Hydrogen Energy 2019, 44, 11168-11184. [CrossRef]

21. Li, T.; Hampp, F.; Lindstedt, R. Experimental study of turbulent explosions in hydrogen enriched syngas related fuels. Process. Saf. Environ. Prot. 2018, 116, 663-676. [CrossRef]

22. Karlis, E.; Liu, Y.; Hardalupas, Y.; Taylor, A.M. $\mathrm{H}_{2}$ enrichment of $\mathrm{CH}_{4}$ blends in lean premixed gas turbine combustion: An experimental study on effects on flame shape and thermoacoustic oscillation dynamics. Fuel 2019, 254, 115524. [CrossRef]

23. Ge, B.; Ji, Y.; Zhang, Z.; Zang, S.; Tian, Y.; Yu, H.; Chen, M.; Jiao, G.; Zhang, D. Experiment study on the combustion performance of hydrogen-enriched natural gas in a DLE burner. Int. J. Hydrogen Energy 2019, 44, 14023-14031. [CrossRef]

24. Wang, Q.; Zhao, Y.; Wu, F.; Bai, J. Study on the combustion characteristics and ignition limits of the methane homogeneous charge compression ignition with hydrogen addition in micro-power devices. Fuel 2019, 236, 354-364. [CrossRef]

25. Benard, P.; Moureau, V.; Lartigue, G.; D'Angelo, Y. Large-Eddy Simulation of a hydrogen enriched methane/air meso-scale combustor. Int. J. Hydrogen Energy 2017, 42, 2397-2410. [CrossRef]

26. Peñaranda, A.; Boggio, S.M.; Lacava, P.; Merola, S.; Irimescu, A. Characterization of flame front propagation during early and late combustion for methane-hydrogen fueling of an optically accessible SI engine. Int. J. Hydrogen Energy 2018, 43, 23538-23557. [CrossRef]

27. Rajpara, P.; Shah, R.; Banerjee, J. Effect of hydrogen addition on combustion and emission characteristics of methane fuelled upward swirl can combustor. Int. J. Hydrogen Energy 2018, 43, 17505-17519. [CrossRef]

28. Wang, J.; Wu, Y.; Zheng, L.; Yu, M.; Pan, R.; Shan, W. Study on the propagation characteristics of hydrogen/methane/air premixed flames in variable cross-section ducts. Process. Saf. Environ. Prot. 2020, 135, 135-143. [CrossRef]

29. Huang, Z.; Zhang, J.; Zhao, Y.; Zhang, H.; Yue, G.; Suda, T.; Narukawa, M. Kinetic studies of char gasification by steam and $\mathrm{CO}_{2}$ in the presence of $\mathrm{H}_{2}$ and CO. Fuel Process. Technol. 2010, 91, 843-847. [CrossRef]

30. Gantenbein, A.; Witte, J.; Biollaz, S.M.; Kröcher, O.; Schildhauer, T.J. Flexible application of biogas upgrading membranes for hydrogen recycle in power-to-methane processes. Chem. Eng. Sci. 2021, 229, 116012. [CrossRef]

31. Karagöz, Y. Analysis of the impact of gasoline, biogas and biogas + hydrogen fuels on emissions and vehicle performance in the WLTC and NEDC. Int. J. Hydrogen Energy 2019, 44, 31621-31632. [CrossRef]

32. Elhawary, S.; Saat, A.; Wahid, M.A.; Ghazali, A.D. Experimental study of using biogas in Pulse Detonation Engine with hydrogen enrichment. Int. J. Hydrogen Energy 2020, 45, 15414-15424. [CrossRef]

33. Talaei, A.; Gemechu, E.; Kumar, A. Key factors affecting greenhouse gas emissions in the Canadian industrial sector: A decomposition analysis. J. Clean. Prod. 2020, 246, 119026. [CrossRef] 
34. Bouguessa, R.; Tarabet, L.; Loubar, K.; Belmrabet, T.; Tazerout, M. Experimental investigation on biogas enrichment with hydrogen for improving the combustion in diesel engine operating under dual fuel mode. Int. J. Hydrogen Energy 2020, 45, $9052-9063$. [CrossRef]

35. Wei, Z.; Zhen, H.; Fu, J.; Leung, C.; Cheung, C.; Huang, Z. Experimental and numerical study on the laminar burning velocity of hydrogen enriched biogas mixture. Int. J. Hydrogen Energy 2019, 44, 22240-22249. [CrossRef]

36. Yan, F.; Xu, L.; Wang, Y. Application of hydrogen enriched natural gas in spark ignition IC engines: From fundamental fuel properties to engine performances and emissions. Renew. Sustain. Energy Rev. 2018, 82, 1457-1488. [CrossRef]

37. Zhao, Y.; McDonell, V.; Samuelsen, S. Assessment of the combustion performance of a room furnace operating on pipeline natural gas mixed with simulated biogas or hydrogen. Int. J. Hydrogen Energy 2020, 45, 11368-11379. [CrossRef]

38. Vaferi, K.; Vajdi, M.; Nekahi, S.; Nekahi, S.; Moghanlou, F.S.; Asl, M.S.; Mohammadi, M. Thermo-mechanical simulation of ultrahigh temperature ceramic composites as alternative materials for gas turbine stator blades. Ceram. Int. 2021, 47, 567-580. [CrossRef]

39. Wei, L.; Geng, P. A review on natural gas/diesel dual fuel combustion, emissions and performance. Fuel Process. Technol. 2016, 142, 264-278. [CrossRef]

40. C. 131. In CSN EN 676 Forced Draught Burners for Gaseous Fuels (Standard); no. 1025; 2020; Volume 10, pp. 2012-2013. Available online: https: / / www.en-standard.eu/csn-en-676-forced-draught-burners-for-gaseous-fuels / (accessed on 14 March 2021).

41. Schofield, K. The enigmatic mechanism of the flame ionization detector: Its overlooked implications for fossil fuel combustion modeling. Prog. Energy Combust. Sci. 2008, 34, 330-350. [CrossRef]

42. CNMC. Comisión Nacional de los Mercados y la Competencia. 2018. Available online: https://www.cnmc.es/ (accessed on 14 March 2021).

43. Zhen, H.S.; Leung, C.W.; Cheung, C.S.; Huang, Z.H. Characterization of biogas-hydrogen premixed flames using Bunsen burner. Int. J. Hydrogen Energy 2014, 39, 13292-13299. [CrossRef]

44. European Commission (EC) for standardization. EN ISO 6976:2016 Natural Gas_Calculation of Calorific Values, Density, Relative Density and Wobbe Indices from Composition; European Union: Brusseles, Belgium, 2017.

45. Zachariahwolff, J.; Egyedi, T.; Hemmes, K. From natural gas to hydrogen via the Wobbe index: The role of standardized gateways in sustainable infrastructure transitions. Int. J. Hydrogen Energy 2007, 32, 1235-1245. [CrossRef]

46. European Parliament and the Council of the European Union. Regulation (EU) 2016/426 of the European Parliament and of the Council of 9 March 2016 on Appliances Burning Gaseous Fuels and Repealing Directive 2009/142/EC (Standard), No. 1025.2016. Available online: https:/ / eur-lex.europa.eu/legal-content/EN/TXT/?uri=uriserv:OJ.L_.2016.081.01.0099.01.ENG (accessed on 14 March 2021).

47. Wei, Z.; Zhen, H.; Leung, C.; Cheung, C.; Huang, Z. Formations and emissions of $\mathrm{CO} / \mathrm{NO}_{2} / \mathrm{NOx}$ in the laminar premixed biogas-hydrogen flame undergoing the flame-wall interaction: Effects of the variable $\mathrm{CO}_{2}$ proportion. Fuel 2020, $276,118096$. [CrossRef]

48. Rocha, N.; Quintino, F.; Fernandes, E. $\mathrm{H}_{2}$ enrichment impact on the chemiluminescence of biogas/air premixed flames. Int. J. Hydrogen Energy 2020, 45, 3233-3250. [CrossRef]

49. Yoon, S.H.; Lee, C.S. Experimental investigation on the combustion and exhaust emission characteristics of biogas-biodiesel dual-fuel combustion in a CI engine. Fuel Process. Technol. 2011, 92, 992-1000. [CrossRef]

50. Lee, W.-S.; Kang, J.-H.; Lee, J.-C.; Lee, C.-H. Enhancement of energy efficiency by exhaust gas recirculation with oxygen-rich combustion in a natural gas combined cycle with a carbon capture process. Energy 2020, 200, 117586. [CrossRef] 